\title{
ACTH LEVELS IN PLASMA IN PREOPERATIVE AND SURGICALLY STRESSED PATIENTS *
}

\author{
By COLLIN E. COOPER † AND DON H. NELSON $\ddagger$
}

(From the Department of Medicine, University of Southern California School of Medicine and Los Angeles County General Hospital, Los Angeles, Calif.)

(Submitted for publication February 6, 1962; accepted April 19, 1962)

ACTH levels in human plasma during surgical stress have not been estimated previously. Much evidence (1-7) has accumulated, however, concerning variations in adrenal cortical steroids in plasma during and after surgery. Although an increase in plasma ACTH with stress has been noted in animal experiments, it has been suggested by some investigators that elevation of corticosteroids in plasma after surgery is controlled by changes in hepatic function and concentration of plasma corticosteroid rather than by a "direct drive" of ACTH release $(8,9)$.

This study was undertaken to determine the ACTH content of plasma samples obtained from

* Supported in part by USPHS Grant no. AF-12,139; Research Grant A-4131; and Clinical Center Grant no. OG-19.

$\dagger$ Postdoctoral Fellow, USPHS. Current address : Resident in Internal Medicine, Los Angeles County Hospital.

$\ddagger$ Investigator, Howard Hughes Medical Institute. patients about to undergo and immediately after an elective operation. In two patients plasma $\mathrm{ACTH}$ was determined simultaneously with plasma corticosteroids.

\section{METHODS}

Four females and six males ranging in age from 17 to 79 years were studied. Subjects selected were patients scheduled to undergo elective surgery at the Los Angeles County General Hospital.

Four plasma samples were obtained from each patient: 1) in the morning, between $6: 30$ and $8: 30$ a.m., before surgery ; 2) 0.5 hour after the end of the operation; 3 ) 4 hours after the end of the operation; and 4) 24 hours after the end of the operation.

Fifty-ml blood samples were drawn through an 18gauge needle into a syringe which had been previously rinsed with heparin $(5,000 \mathrm{U}$ per $\mathrm{ml})$. The sample was placed in a tube surrounded by crushed ice and the plasma was separated within 30 minutes in a refrigerated centrifuge. The plasma was quickly frozen to $-20^{\circ} \mathrm{C}$ for storage and was thawed just prior to assay.

The plasma samples obtained from the patients were

TABLE I

Patients studied and operations performed

\begin{tabular}{|c|c|c|c|c|c|}
\hline Patients & Age & Sex & $\begin{array}{c}\text { Major anesthetic } \\
\text { agent }\end{array}$ & Surgery performed & $\begin{array}{l}\text { Duration } \\
\text { of operation }\end{array}$ \\
\hline E.D. & 58 & $\mathbf{F}$ & Nitrous oxide & Abdominoperineal resection & $\begin{array}{l}\text { hrs } \\
1.75\end{array}$ \\
\hline J.G. & 25 & $\mathbf{M}$ & Cyclopropane & Thyroidectomy & 3.75 \\
\hline A.T. & 27 & $\mathrm{~F}$ & Nitrous oxide & $\begin{array}{l}\text { Right colectomy plus resection } \\
\text { of terminal ileum }\end{array}$ & 2.25 \\
\hline J.Bel. & 47 & $\mathbf{M}$ & Nitrous oxide & $\begin{array}{l}\text { Radical resection right mandible } \\
\text { plus right radical neck dissection }\end{array}$ & 3.0 \\
\hline H.A. & 79 & $\mathbf{F}$ & Nitrous oxide & $\begin{array}{l}\text { Cholecystectomy plus common } \\
\text { duct exploration }\end{array}$ & 2.25 \\
\hline B.G. & 40 & $\mathbf{F}$ & Nitrous oxide & Excisional biopsy left breast & 1.25 \\
\hline J.W. & 17 & $\mathbf{M}$ & Nitrous oxide & $\begin{array}{l}\text { Thoracotomy plus biopsy hilar } \\
\text { mass }\end{array}$ & 4.0 \\
\hline J.B. & 74 & $\mathrm{~F}$ & Cyclopropane & $\begin{array}{l}\text { Cholecystectomy plus common } \\
\text { duct exploration }\end{array}$ & 3.0 \\
\hline M.W. & 63 & $\mathbf{M}$ & Cyclopropane & $\begin{array}{l}\text { Cholecystectomy plus common } \\
\text { duct exploration }\end{array}$ & 4.0 \\
\hline M.T. & 63 & F & Cyclopropane & $\begin{array}{l}\text { Exploratory laparotomy plus } \\
\text { biopsy of liver and pancreas }\end{array}$ & 3.0 \\
\hline
\end{tabular}


TABLE II

$A C T H$ responses calculated on the basis of a single day's assay

\begin{tabular}{|c|c|c|c|c|c|}
\hline \multirow[b]{2}{*}{ Patient } & \multicolumn{4}{|c|}{ Plasma ACTH } & \multirow[b]{2}{*}{ Lambda } \\
\hline & Preop. & $\begin{array}{l}\text { 0.5 hr } \\
\text { P.op. }\end{array}$ & $\begin{array}{l}4 \text { hrs } \\
\text { P. op. }\end{array}$ & $\begin{array}{l}24 \mathrm{hrs} \\
\text { P. op. }\end{array}$ & \\
\hline & \multicolumn{2}{|c|}{$m U / 100 \mathrm{ml}$ plasma } & \multicolumn{2}{|c|}{$m U / 100 m l$ plasma } & \\
\hline 1. E.D. & NS * & 3.2 & 1.0 & NS & 0.11 \\
\hline 2. J.G. & NS & 1.3 & 0.6 & NS & 0.11 \\
\hline 3. A.T. & NS & 0.9 & NS & 0.7 & 0.13 \\
\hline 4. J.Bel. & 0.6 & 1.5 & 2.0 & NS & 0.12 \\
\hline 5. H.A. & NS & 3.6 & NS & NS & 0.12 \\
\hline 6. B.G. & 0.6 & 1.2 & & & 0.13 \\
\hline 7. J.W. & NS & 4.7 & NS & NS & 0.11 \\
\hline 8. J.B. & NS & NS & 0.9 & 0.8 & 0.10 \\
\hline 9. M.W. & 0.9 & 1.3 & 1.0 & 0.8 & 0.13 \\
\hline 10. M.T. & NS & 1.3 & 1.1 & 0.6 & 0.12 \\
\hline
\end{tabular}

* NS = not significantly different from zero.

assayed by a slight modification of the Lipscomb-Nelson method $(10,11)$. Male albino rats of the SpragueDawley strain, hypophysectomized for exactly 2 hours, were used. The rats, which had been under ether anesthesia since hypophysectomy, were given $120 \mathrm{U}$ of sodium heparin by the left femoral vein. The test sample (whether standard, unknown, or control solution) was then injected into the right femoral vein. It has been shown in this laboratory that excessive animal mortality occurs if the volume of injected plasma exceeds $5 \mathrm{ml}$. Therefore, the volume routinely injected was $5 \mathrm{ml}$, but a smaller volume was used if a high ACTH level was expected. The use of a smaller volume of plasma when the ACTH level was high prevented the response to the unknown from exceeding that of the highest standard dose.

Left adrenal vein cannulation was performed through a horizontal abdominal incision by passing a hubless 21gauge needle with polyethylene catheter attached through the inferior border of the renal vein into the orifice of the adrenal vein exactly 3 minutes after injection of the sample. With the animal thus prepared, bleeding was allowed to proceed for exactly 20 minutes. The rat plasma was assayed for corticosterone by the sulfuric acid fluorescence method of Silber, Busch and Oslapas (12).

ACTH levels were calculated by comparing corticosterone secretion in the 20 -minute collection period after injection of 0.03 and $0.06 \mathrm{mU}$ ACTH (USP standard corticotropin, $1.14 \mathrm{U}$ per $\mathrm{mg}$ ) with the response to samples of patient plasma. Data in press (11) have demonstrated that the response to the log dose is linear up to $0.1 \mathrm{mU}$. Statistical analysis was based on the procedure followed by Sayers, Sayers and Woodbury (13). Calculation of significance of differences between responses to standard and unknown plasma samples was made according to Student's $t$ test; $\mathrm{p}$ values were obtained by using standard tables (14). Values obtained were calculated in two ways: 1 ) the values obtained on one day (an average of 18 rats) were treated as a single assay (see Table II) ; and 2) all of the responses to control or standard solutions and to patients' plasma samples obtained during the 2-month period (a total of 178 rats) are grouped together (see Table III).

Whenever possible, three rats were used to obtain a single unknown or standard value. Owing to the death

TABLE III

Corticosterone responses to ACTH by assay animals, with statistical comparison *

\begin{tabular}{|c|c|c|c|c|c|c|c|c|}
\hline \multirow[b]{2}{*}{ Sample } & \multirow{2}{*}{$\begin{array}{l}\text { No. of } \\
\text { rats }\end{array}$} & \multicolumn{2}{|c|}{ Corticosterone } & \multicolumn{5}{|c|}{ Comparison of groups, $\mathfrak{p}$ values } \\
\hline & & Mean & SE & Control & 0.03 & 0.06 & Preop. & $4 \mathrm{hrs}$ \\
\hline & & \multicolumn{2}{|c|}{$\mu g / 20 \min$} & & & & & \\
\hline Controls & 38 & 0.127 & 0.013 & & & & & \\
\hline $\begin{array}{l}\text { Standard solution, } \\
0.03 \mathrm{mU} \text { ACTH (\%) }\end{array}$ & 36 & 0.189 & 0.015 & 0.01 & & & & \\
\hline $\begin{array}{l}\text { Standard solution, } \\
0.06 \mathrm{mU} \text { ACTH }(\%)\end{array}$ & 27 & 0.722 & 0.092 & 0.001 & 0.001 & & & \\
\hline Preop. & 20 & 0.269 & 0.058 & 0.02 & NS & 0.001 & & \\
\hline 0.5 hr P. op. & 20 & 1.280 & 0.187 & 0.001 & 0.001 & 0.02 & 0.001 & 0.02 \\
\hline 4 hrs P. op. & 19 & 0.639 & 0.175 & 0.01 & 0.01 & NS & 0.05 & \\
\hline 24 hrs P. op. & 18 & 0.268 & 0.043 & 0.01 & NS & 0.001 & NS & 0.05 \\
\hline
\end{tabular}

* Grouped results from 10 patients and 178 assay animals. 


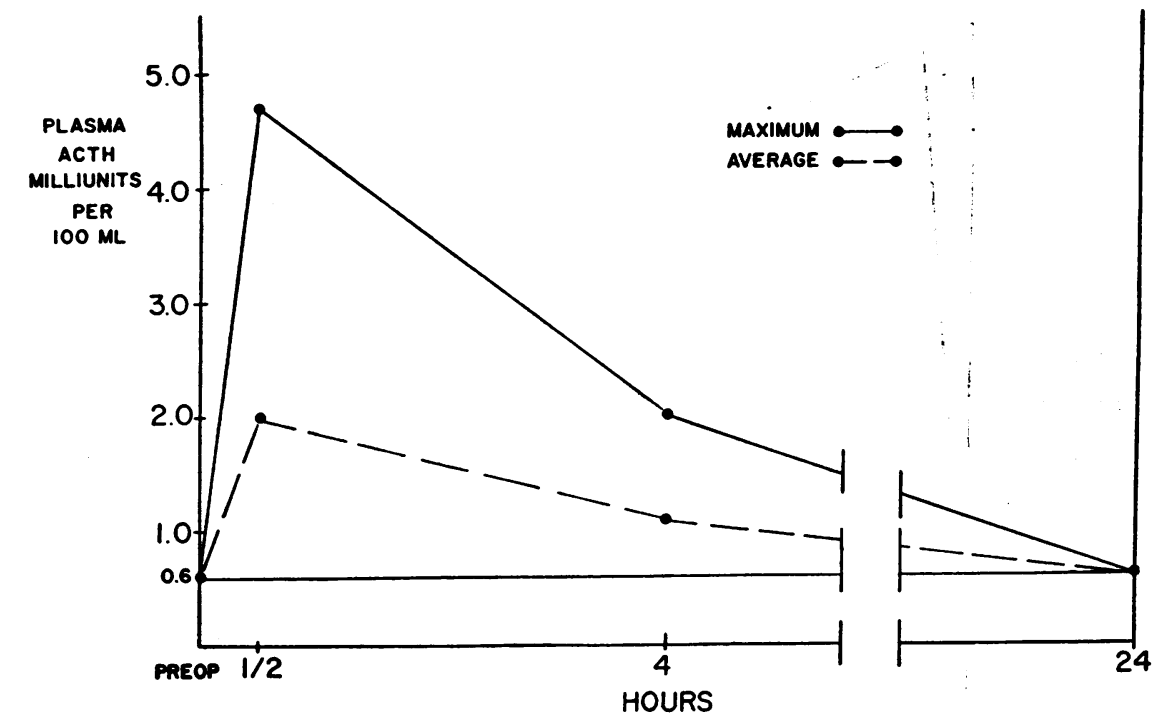

Fig. 1. Maximum and average ACTH values found in plasma preoperatively AND AT $0.5,4$, AND 24 hOURS POSTOPERATIVELY IN THE TEN PATIENTS STUdIED. The $0.6 \mathrm{mU}$ level represents the lowest detectable and approximately normal ACTH level in plasma, as measured by the method used.

of the animals during the procedure or to other laboratory accidents, this was not always possible. Nevertheless, values for each point represent the corticosteroid responses of at least two rats.

\section{RESULTS}

Table I summarizes the data on the patients in this study according to age, sex, anesthesia, type of surgery performed, and duration of surgery. All of the patients had uneventful postoperative recoveries except J. Bel., who died on the third postoperative day.

The ACTH values found in plasma at each time interval for the ten patients are shown in Table II. The individual values were obtained by reading from a dose-response line whose slope was determined on the basis of standards assayed the same day. The slope of the line and consequently its

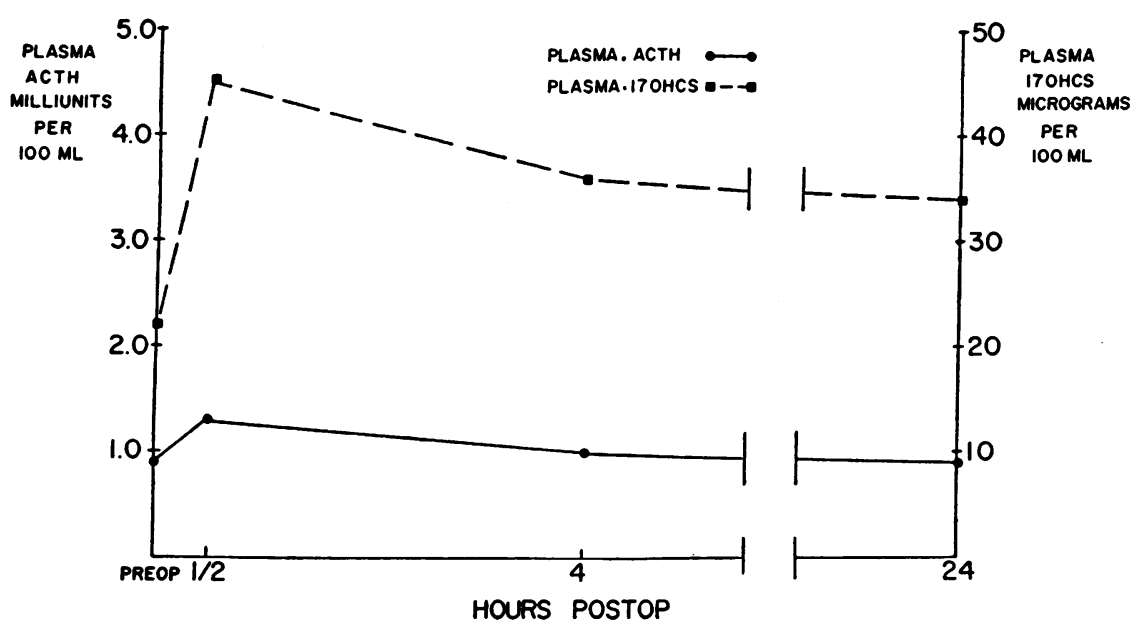

Fig. 2. ACTH AND 17-hydroxycorticosteroid values Found in PLASMa of PATIENT 9 PREOPERATIVELy AND AT $0.5,4$, AND 24 hours POSTOPERATIVEly. A small increase in plasma ACTH is accompanied by a marked increase in plasma 17-hydroxycorticosteroids. 


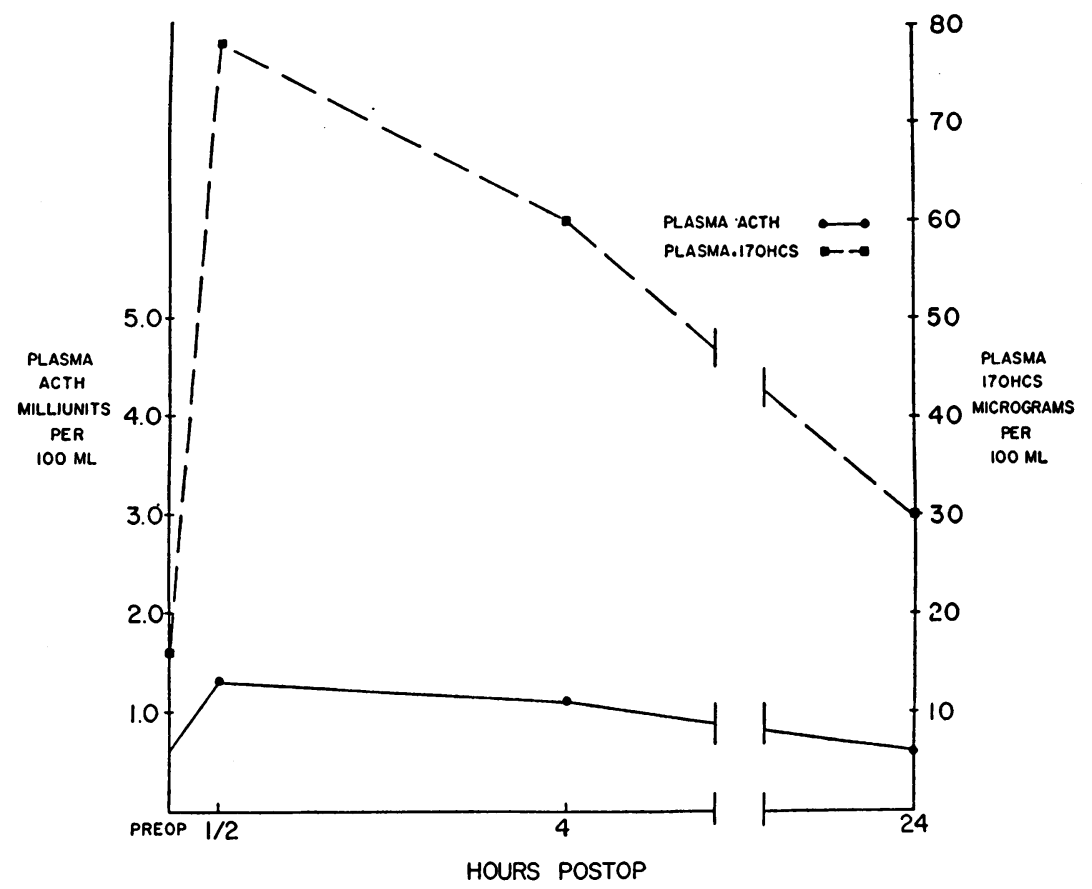

Fig. 3. ACTH AND 17-HydRoxycorticosteroid values FOUND IN PLASMa OF PATIENT 10 PREOPERATIVELY AND AT $0.5,4$, AND 24 HOURS POSTOPERATIVELY.

lambda value was computed by the method of Sayers and co-workers (13).

When all of the results were recorded (as micrograms of corticosterone secreted per 20 minutes) and were grouped according to interval (preoperative, 0.5 hour, 4 , or 24 hours postoperatively) as tabulated in Table III, it became evident that there was a statistically significant difference between the results in those groups which showed no significant difference in a single day's assay.

Thus, although data obtained from a single day's assay were insufficient to demonstrate a statistically significant difference between control responses and responses to preoperative or postoperative plasma samples, grouping of the data as shown indicates such a difference ( $p=0.01$ to 0.02 ). Similarly, the significant increase in plasma ACTH over preoperative values which occurred at the 0.5 hour and 4-hour postoperative intervals was substantiated statistically. The highest level of plasma ACTH measured was found in the immediate postoperative period, as indicated by the highest output of corticosterone during the 20-minute collection period in the assay animals (Figure 1).

Levels of 17-hydroxycorticosteroids and ACTH were determined simultaneously on samples of plasma from two patients (M.W. and M.T.). These results are depicted in Figures 2 and 3 and are similar for both patients. The maximum increase in plasma 17-hydroxycorticosteroids and ACTH occurred 0.5 hour postoperatively. Despite the fall of ACTH to control levels, plasma 17-hydroxycorticosteroids, although decreased from peak levels, remained elevated above normal for 24 hours after surgery.

\section{DISCUSSION}

Since a method has been available for determining plasma 17-hydroxycorticosteroids (15), the levels of plasma adrenocortical hormones during and after surgery have been determined by many workers $(1-7,16,17)$. Although there are differences in individual responses to surgery in terms of plasma 17-hydroxycorticosteroids as influenced by duration of surgery, severity of surgery, anesthesia, and postoperative complications, certain generalizations concerning the magnitude and duration of elevation of plasma corticosteroids can be made. After the initial rise and fall with anesthesia, there is a gradual increase in 17-hydroxycorticosteroids during surgery. The rate of this increase and the eventual magnitude are ob- 
viously dependent upon the above variables. At the end of surgery, the plasma 17-hydroxycorticosteroids remain elevated for a few hours and then return gradually to normal. Twenty-four hours after the surgical stress, if no postoperative complications have supervened, the plasma 17hydroxycorticosteroids are usually again normal.

The mechanism(s) responsible for this now well documented change in plasma steroids is controversial. The importance of the liver in the metabolism of the adrenal hormones in the dog, as demonstrated by Nelson and Harding (18), and in man, as shown shortly thereafter by Tyler and coworkers (19), is now well documented. Englert, Brown, Wallach and Simons (20) demonstrated that even a severely diseased liver was able to conjugate steroids but was not able to reduce the $A$ ring of the steroid molecule. Reduction of the molecule was shown to precede conjugation. Acute and transient changes in liver function in terms of BSP clearance were demonstrated in patients anesthetized or operated upon, or both, and it was suggested that levels of 17 -hydroxycorticosteroids were roughly correlated with reduction in the liver's ability to clear BSP. A similar explanation for increased plasma corticosteroids in the rat has been given by Urquhart and Yates and co-workers $(8,9)$ who stated that the liver exerted a controlling influence on adrenocortical function. Conflicting evidence has been presented as to whether conjugated steroids actually rise in the few hours after surgery $(5,7)$. All authors (5, $7,21)$ are agreed that free cortisol increases and is not handled in a normal manner by the liver, under the "stress" of surgery. Other studies (2224) document the increase of plasma 17-hydroxycorticosteroids in other "stressful" situations in animals as well as in man.

Evidence, based on experiments in animals, is available to help assess the role of the pituitary in producing the increase in plasma 17-hydroxycorticosteroids after stress. Sayers and Sayers (25) showed the dependence of the adrenal ascorbic acid depletion which occurs after stress (cold, heat, histamine, and typhoid) upon an intact pituitary gland in the rat. Taylor, Albert and Sprague (26), Paris and co-workers (27), Sayers (28), and Bethune, Nelson and Thorn (29) have documented elevated plasma ACTH levels in Addi- sonian patients but not in normal subjects after surgery or other stress. These investigators were unable to detect $\mathrm{ACTH}$ in the plasma of normal subjects. Plasma ACTH is found to be consistently elevated in subjects with untreated Addison's disease or untreated congenital adrenal hyperplasia in whom the plasma 17-hydroxycorticosteroid level is markedly diminished or absent. These elevated ACTH levels disappear when adrenal steroids are given to the patient (29). Paris and co-workers (27) recorded elevated ACTH levels in a patient with a "pheochromocytoma" and in one patient with Cushing's syndrome due to an adrenal cortical tumor. More recently, an even more pronounced increase in plasma ACTH has been observed in a number of patients in whom a pituitary tumor has been found after adrenalectomy for Cushing's syndrome (30). Hale and associates (31), using hypoxia or hypoxia plus heat as stressors, found that whereas "certain individuals responded with an increase in 17-hydroxycorticosteroids, there were no changes in ACTH titer detectable" (ascorbic acid-depletion assay). The subjects tested by Hale were found to have nondetectable levels of ACTH or less than $0.5 \mathrm{mU}$ ACTH per $100 \mathrm{ml}$ plasma.

From an analysis of the data obtained in this study, several facts are apparent. The data suggest a mean preoperative ACTH level in plasma of $0.6 \mathrm{mU}$ per $100 \mathrm{ml}$ for the ten patients. No difference in ACTH content of plasma was detectable between these ten patients in the preoperative period and the "normal" subjects who have been studied by this technique (32). None of the preoperative values exceeded $0.9 \mathrm{mU}$ per $100 \mathrm{ml}$.

The plasma ACTH was generally at a peak value in the 0.5 -hour sample, but two individuals had higher values in the 4-hour specimens. In this respect there is apparent individual variation. The diurnal variation in plasma ACTH, if any, remains to be determined. The peak elevation of plasma ACTH may occur during or after surgery. Plasma ACTH appears to return to normal 24 hours after surgery and may return to normal in some individuals 4 hours after the end of surgery.

Of interest is the apparent lack of function of the "feedback" mechanism used to describe the control of ACTH secretion. In the two patients studied with simultaneous plasma corticoid and ACTH 
determinations, it can be seen that the plasma ACTH and the plasma 17-hydroxycorticosteroids rise and fall together, not reciprocally. The increase in plasma ACTH appears from this study to be an active process during surgery which is not suppressed by the observed increase in plasma corticosteroids. This is in agreement with previous studies carried out in the dog (33). Although pituitary output of ACTH would be easily suppressed in the normal or nonstressed Addisonian by the plasma levels of cortisol achieved in patients undergoing the stress of surgery (29), such has not occurred in these patients, and simultaneously elevated levels of plasma corticosteroids and plasma ACTH were found to be present. The failure of increased plasma corticosteroids to suppress the increase in plasma ACTH is indicative of a direct stimulus to ACTH secretion rather than a dependence on variations in blood corticosteroids.

\section{SUM MARY}

Ten patients, undergoing elective surgery at the Los Angeles County General Hospital, had preoperative and postoperative blood samples drawn for determination of plasma ACTH. Plasma 17hydroxycorticosteroids were determined on the same samples in two of these patients.

The plasma ACTH was determined by a slight modification of the Lipscomb-Nelson assay, which involves estimation of corticosterone in the adrenal venous blood of rats 2 hours after hypophysectomy. The assay as used in this study is described.

All of the plasma ACTH levels in the preoperative samples were within the "normal" range for this laboratory. Most of the samples studied 0.5 hour after the operation had elevated levels, which returned toward normal by 4 hours, and all were normal by 24 hours postoperatively. As a group, the ACTH levels in the preoperative and 24-hour postoperative plasma samples were indistinguishable from each other and equivalent to approximately $0.6 \mathrm{mU}$ per $100 \mathrm{ml}$ plasma.

The previous evidence for plasma corticoid elevation during surgery, together with suggested mechanisms, is presented and discussed. An increase in plasma ACTH occurred coincident with an elevation in plasma corticosteroids, which under these circumstances failed to produce a suppression of plasma ACTH.

\section{ACKNOWLEDGMENTS}

The authors wish to acknowledge the excellent assistance of Mr. E. Ray Rutherford, Misses Julia Bell, Caroleen Lockwood, Cynthia Harris and Anne Dempsey. We are particularly indebted to Doctors Douglas Smiley and Laird Facey and their colleagues of the surgical staff at the Los Angeles County General Hospital, who aided us in the collection of samples from the patients included in this study.

\section{REFERENCES}

1. Steenburg, R. W., Lennihan, R., and Moore, F. D. Studies in surgical endocrinology. II. The free blood 17-hydroxycorticoids in surgical patients; their relation to urine steroids, metabolism and convalescence. Ann. Surg. 1956, 143, 180.

2. Sandberg, A. A., Eik-Nes, K., Samuels, L. T., and Tyler, F. H. The effects of surgery on the blood levels and metabolism of 17-hydroxycorticosteroids in man. J. clin. Invest. 1954, 33, 1509.

3. Viikari, S. J., and Thomasson, B. H. On the changes in plasma 17-hydroxycorticosteroid levels during surgical procedures. Acta endocr. (Kbh.) 1957, 24, 361.

4. Elman, R., Weichselbaum, T. E., Moncrief, J. C., and Margraf, H. W. Adrenal cortical steroids following elective operations: Quantitative studies in the peripheral plasma of 17-hydroxy- and 17desoxycorticosteroids. Arch. Surg. (Chicago) 1955, 71, 697.

5. Murray, J. O. S., Marks, L. J., Colombo, F. V., Josephs, B., Leftin, J. H., and Leonard, M. P. The effect of surgical operation on the plasma clearance of infused cortisol. Ann. Surg. 1958, 148, 951.

6. Estabrooks, R. A., Marks, L. J., Lonergan, J. C., Murtaugh, J. F., and Strobl, V. E. The effect of surgical operation on the adrenocortical response to ACTH. Ann. Surg. 1959, 150, 941.

7. Steenburg, R. W., Smith, L. L., and Moore, F. D. Conjugated 17-hydroxycorticosteroids in plasma: Measurement and significance in relation to surgical trauma. J. clin. Endocr. 1961, 21, 39.

8. Urquhart, J., Yates, F. E., and Herbst, A. L. Hepatic regulation of adrenal cortical function. Endocrinology 1959, 64, 816.

9. Yates, F. E., Leeman, S. E., Glenister, D. W., and Dallman, M. F. Interaction between plasma corticosterone concentration and adrenocorticotropinreleasing stimuli in the rat: Evidence for the reset of an endocrine feedback control. Endocrinology 1961, 69, 67.

10. Lipscomb, H., and Nelson, D. H. Measurement of corticosterone in rat adrenal venous plasma as bioassay for ACTH. Fed. Proc. 1959, 18, 95.

11. Lipscomb, H., and Nelson, D. H. A sensitive biological assay for ACTH. Endocrinology. In press.

12. Silber, R. H., Busch, R. D., and Oslapas, R. Practical procedure for estimation of corticosterone or hydrocortisone. Clin. Chem. 1958, 4, 278. 
13. Sayers, M. A., Sayers, G., and Woodbury, L. A. The assay of adrenocorticotropic hormone by the adrenal ascorbic acid-depletion method. Endocrinology 1948, 42, 379.

14. Fisher, R. A., and Yates, F. Statistical Tables for Biological, Agricultural and Medical Research, 4th ed. New York, Hafner, 1953.

15. Nelson, D. H., and Samuels, L. T. A method for the determination of 17-hydroxycorticosteroids in blood: 17-Hydroxycorticosterone in the peripheral circulation. J. clin. Endocr. 1952, 12, 519.

16. Moore, F. D. Discussion on the endocrine response to surgery. Proc. roy. Soc. Med. 1955, 48, 817.

17. Franksson, C., and Gemzell, C. A. Blood levels of 17-hydroxycorticosteroids in surgery and allied conditions. Acta chir. scand. 1953, 106, 24.

18. Nelson, D. H., and Harding, B. Effect of liver on blood levels of 17-hydroxycorticosteroids in the dog. Fed. Proc. 1952, 11, 379.

19. Tyler, F. H., Schmidt, C. D., Eik-Nes, K., Brown, H., and Samuels, L. T. The role of the liver and the adrenal in producing elevated plasma 17-hydroxycorticosteroid levels in surgery. J. clin. Invest. 1954, 33, 1517.

20. Englert, E., Jr., Brown, H., Wallach, S., and Simons, E. L. Metabolism of free and conjugated 17hydroxycorticosteroids in subjects with liver disease. J. clin. Endocr. 1957, 17, 1395.

21. Steenburg, R. W., and Ganong, W. F. Observations on the influence of extra-adrenal factors on circulating 17-hydroxycorticosteroids in the surgically stressed, adrenalectomized animal. Surgery 1955, 38, 92.

22. McLaughlin, J., Jr., and Gray, I. Biochemical response to trauma. IV. Corticosteroid levels in plasma of rats subjected to tumbling trauma. Amer. J. Physiol. 1959, 196, 893.

23. Bliss, E. L., Migeon, C. J., Eik-Nes, K., Sandberg, A. A., and Samuels, L. T. The effects of insulin, histamine, bacterial pyrogen, and the antabuse- alcohol reaction upon the levels of 17 -hydroxycorticosteroids in the peripheral blood of man. Metabolism 1954, 3, 493.

24. Hume, D. M., Nelson, D. H., and Miller, D. W. Blood and urinary 17-hydroxycorticosteroids in patients with severe burns. Ann. Surg. 1956, 143, 316.

25. Sayers, G., and Sayers, M. A. Regulation of pituitary adrenocorticotrophic activity during the response of the rat to acute stress. Endocrinology 1947, 40, 265.

26. Taylor, A. B., Albert, A., and Sprague, R. G. Adrenotrophic activity of human blood. Endocrinology 1949, 45, 335.

27. Paris, J., Upson, M., Jr., Sprague, R. G., Salassa, R. M., and Albert, A. Corticotropic activity of human blood. J. clin. Endocr. 1954, 14, 597.

28. Sayers, G. Blood ACTH: An Editorial. J. clin. Endocr. 1955, 15, 754.

29. Bethune, J. E., Nelson, D. H., and Thorn, G. W. Plasma adrenocorticotrophic hormone in Addison's disease and its modification by the administration of adrenal steroids. J. clin. Invest. 1957, 36, 1701.

30. Nelson, D. H., Meakin, J. W., and Thorn, G. W. ACTH-producing pituitary tumors following adrenalectomy for Cushing's syndrome. Ann. intern. Med. 1960, 52, 560.

31. Hale, H. B., Sayers, G., Sydnor, K. L., Sweat, M. L., and van Fossan, D. D. Blood adrenocorticotrophic hormone and plasma corticosteroids in men exposed to adverse environmental conditions. J. clin. Invest. 1957, 36, 1642.

32. Cooper, C. E., and Nelson, D. H. Unpublished data.

33. Hume, D. M., Egdahl, R. H., and Nelson, D. H. Effect of hypothermia on pituitary ACTH release and on adrenal cortical and medullary secretion in the dog in Physiology of Induced Hypothermia, R. D. Dripps, Ed. Publication 451, Nat. Acad. Sci. Nat. Res. Council, Washington, D. C., 1956, p. 170. 